\title{
APLIKASI SISTEM PENGELOLAAN ATK (ALAT TULIS KANTOR) AKADEMI ANGKATAN UDARA YOGYAKARTA
}

\author{
Deny Wiria Nugraha ${ }^{1}$, Imat Rahmat Hidayat ${ }^{2}$ \\ ${ }^{1}$ Jurusan Teknik Elektro Universitas Tadulako \\ Palu - Sulawesi Tengah \\ 2 Jurusan Teknik Elektro UGM Yogyakarta \\ Akademi Angkatan Udara Indonesia \\ Imat96@gmail.com
}

\begin{abstract}
Information Systems is an essential requirement for every company or government agency. Included in the Air Force Academy in Yogyakarta, information systems becomes an important component in the system run. Among them is the Stationery Office Management System that has a very high complexity. ATK management system requirements in the Air Force Academy Yogyakarta is needed. Because the extent of management systems that run. So management needs ATK becomes very important. Due to a very large nominal amount if calculated in the long term in accordance with the procurement conducted. This is to reduce errors in the recording which was done manually. Development method makes the system using the waterfall is running ssuai sisem needs. So the rate of change and improvement that occurred in the system will run continuously.

Keyword : Aplication, Information System, Management

Sistem Informasi merupakan kebutuhan mendasar bagi tiap perusahaan atau instansi pemerintahan. Termasuk di Akademi Angkatan Udara Yogyakarta, Sistem informasi menjadi suatu komponen penting dalam sistem yang dijalankan. Diantaranya adalah Sistem Pengelolaan Alat Tulis Kantor yang memiliki kompleksitas yang sangat tinggi. Kebutuhan sistem pengelolaan ATK di Akadmi Angkatan Udara Yogyakarta sangat diperlukan. Karena luasnya sistem manajemen yang dijalankan. Sehingga kebutuhan manajemen ATK menjadi sangat penting. Dikarenakan jumlah nominalnya yang sangat besar jika dihitung dalam jangka waktu yang panjang sesuai dengan pengadaan yang dilakukan. Hal ini untuk mengurangi kesalahan dalam pencatatan yang dilakukan secara manual. Metode pengembanga sistem yang menggunakan waterfall menjadikan sisem ini berjalan ssuai dengan kebutuhan. Sehingga tingkat perubahan dan perbaikan yang terjadi pada sistem akan berlangsung terus-menerus.

Kata kunci : Aplikasi, Sistem Informasi, Manajemen
\end{abstract}

\section{PENDAHULUAN}

Sistem Pengelolaan ATK (Alat-alat Tulis Kantor) di Akademi Angkatan Udara Yogyakarta pada saat ini masih dilaksanakan secara manual, dengan demikian masih sering terjadinya kesalahan informasi .Dengan kesalahan-kesalahan informasi tersebut, mengakibatkan lambatnya pembuatan laporan rencana pemakaian barang untuk pengajuan anggaran tahun yang akan datang. Dinas Logistik yang berperan sebagai pemasok barang-barang ATK, terlambat menerima laporan dari bagian perlengkapan, keterlambatan pemasokan barangbarang ATK ini secara tidak langsung akan mempengaruhi proses lamanya pendidikan yang ada di masing-masing unit kerja.

Setiap unit kerja/instansi pada akhir tahun harus mengajukan rencana pemakaian ATK tahun berikutnya kepada bagian perlengkapan. Bagian perlengkapan kemudian membuat rencana anggaran pemakaian ATK. Agar rencana anggaran yang dibuat dapat mencukupi kebutuhan ATK tahun berikutnya, maka perlu data tahunan tentang pemakaian ATK. Adakalanya jumlah barang yang tercatat tidak sesuai dengan jumlah barang yang ada di gudang, sehingga perlu adanya transaksi penyesuaian jumlah barang. Data yang harus dicatat adalah rencana pemakaian barang setiap unit kerja/instansi, transaksi pemakaian barang, transaksi pengadaan barang, transaksi penyesuaian barang, serta data awal barang.

Dengan adanya permasalahan tersebut diatas perlu adanya suatu sistem informasi dalam pengelolaan ATK. 


\section{RUMUSAN MASALAH}

Dari tema penelitian yang diambil, maka dapat diambil permasalahan utama yaitu bagaimana membuat sistem pengelolaan alat tulis kantor agar keterlambatan pembuatan laporan dan penerimaan laporan kepada bagian logistik tidak terlambat. Hal ini bertujuan untul mengurangi atau bahkan menghilangkan keterlambatan pengiriman laporan dan agar tidak mengganggu proses pendidikan yang berlangsung.

\section{TUJUAN}

Tujuan dari diadakannya penelitian ini adalah :

a. Membuat suatu rancangan sistem informasi pengelolaan ATK yang diharapkan dapat membantu dan mempercepat proses pembuatan laporan pemakaian ATK

b. Mengurangi kesalahan informasi sehingga akan menghasilkan laporan-laporan yang dapat dipertanggungjawabkan.

\section{RANCANGAN DAN ANALISA SISTEM}

\subsection{Diagram konteks}

Pertama kali yang akan kita buat adalah diagram konteks. Untuk membuat suatu diagram konteks, kita analisa terlebih dahulu sistem informasi yang akan kita buat akan menghasilkan informasi apa saja serta membutuhkan data apa saja, dan selanjutnya kita tentukan sumber data yang dibutuhkan sistem dan tujuan informasi yang dihasilkan sistem. Setelah kita berhasil mendeskripsikan kebutuhan data dan informasi yang harus dihasilkan, kita gambarkan sebuah panah mewakili data/informasi. Dari analisa yang kita lakukan, kita peroleh diagram konteks sebagai berikut:

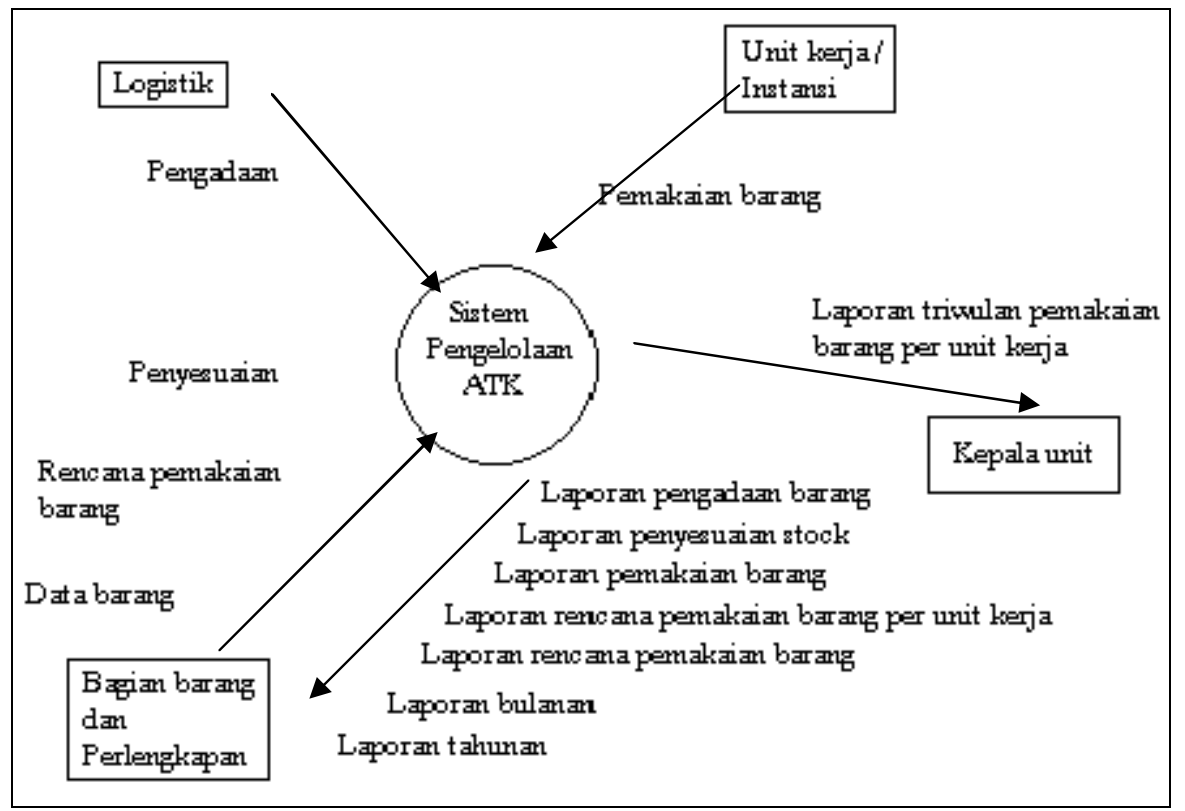

Gambar 1. Diagram Konteks Sistem Informasi Pengelolaan ATK

Pada gambar 1 terlihat bahwa pada Sistem pengelolaan ATK terdapat 4 (empat) komponen yang bekerja di dalam sistem. Yaitu bagian Logistik, Unit Kerja atau instansi, bagian barang dan perlengkapan, serta Kepala Unit. Keempat komponen ini bekerja sesuai dengan tanggung jawab nya. Dimana tiap komponen memiliki level keanggotaan dan login yang disesuaikan dengan kebutuhan serta tanggung jawab di tiap komponennya. 


\subsection{Data Flow Diagram}

Langkah berikutnya adalah menurunkan Diagram konteks dalam bentuk yang lebih detil, yaitu Data Flow Diagram (DFD). Turunan pertama dari diagram konteks adalah DFD Level 0. Bila dalam DFD Level 0 yang kita buat terdapat proses-proses yang masih terlalu global dan dirasa perlu untuk diturunkan lagi, maka DFD Level 0 tersebut kita turunkan menjadi DFD Level 1. Yang perlu diingat pada proses ini adalah bahwa kita tidak diharuskan menurunkan setiap proses yang ada dalam DFD. Ada kemungkinan bahwa suatu proses dalam DFD dirasa kurang detil dan kita turunkan menjadi DFD yang lebih detil, sementara proses yang lain mungkin tidak perlu diturunkan lagi. Pada tahap ini kita harus mendeskripsikan tempat penyimpanan data yang masuk ke sistem. DFD Level 0 dan level 1 dari sistem adalah sebagai berikut.

\subsubsection{DFD Level 0}

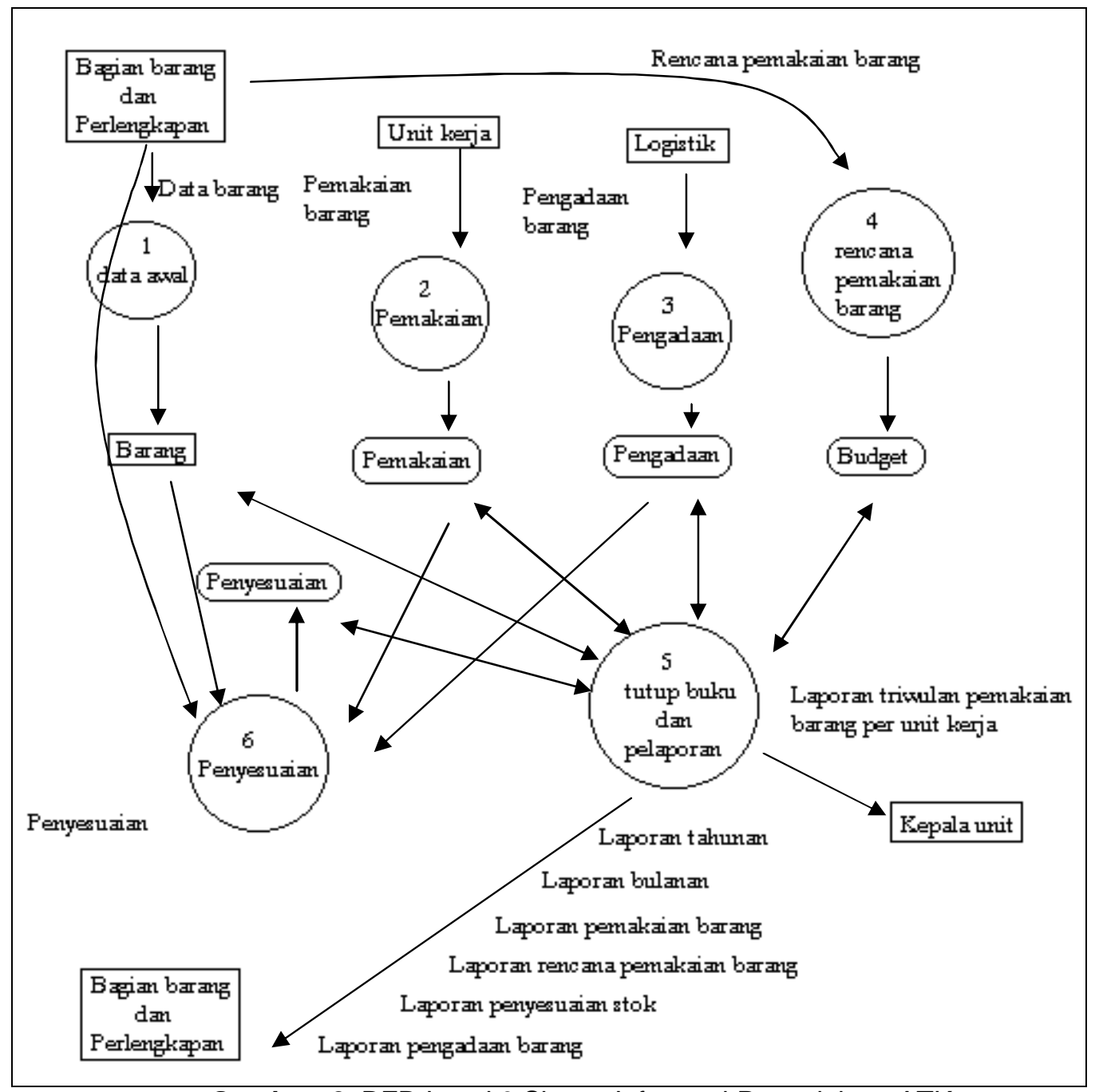

Gambar 2. DFD Level 0 Sistem Informasi Pengelolaan ATK

Pada DFD level 0 terlihat bahwa tiap sistem memiliki proses pengelolaan terhadap komponen yang ada. Pada unit Bagian barang dan perlengakapan terdapat 3 proses yang dijalankan, yaitu proses data awal, proses rencana pemakaian barang dan proses penyesuaian. Pada bagian unit kerja hanya terhubung dengan proses pemakaian. Bagian logistik terhubung dengan proses pengadaan. Serta kepala unit mendapatkan laporan dari proses tutup buku dan pelaporan. 


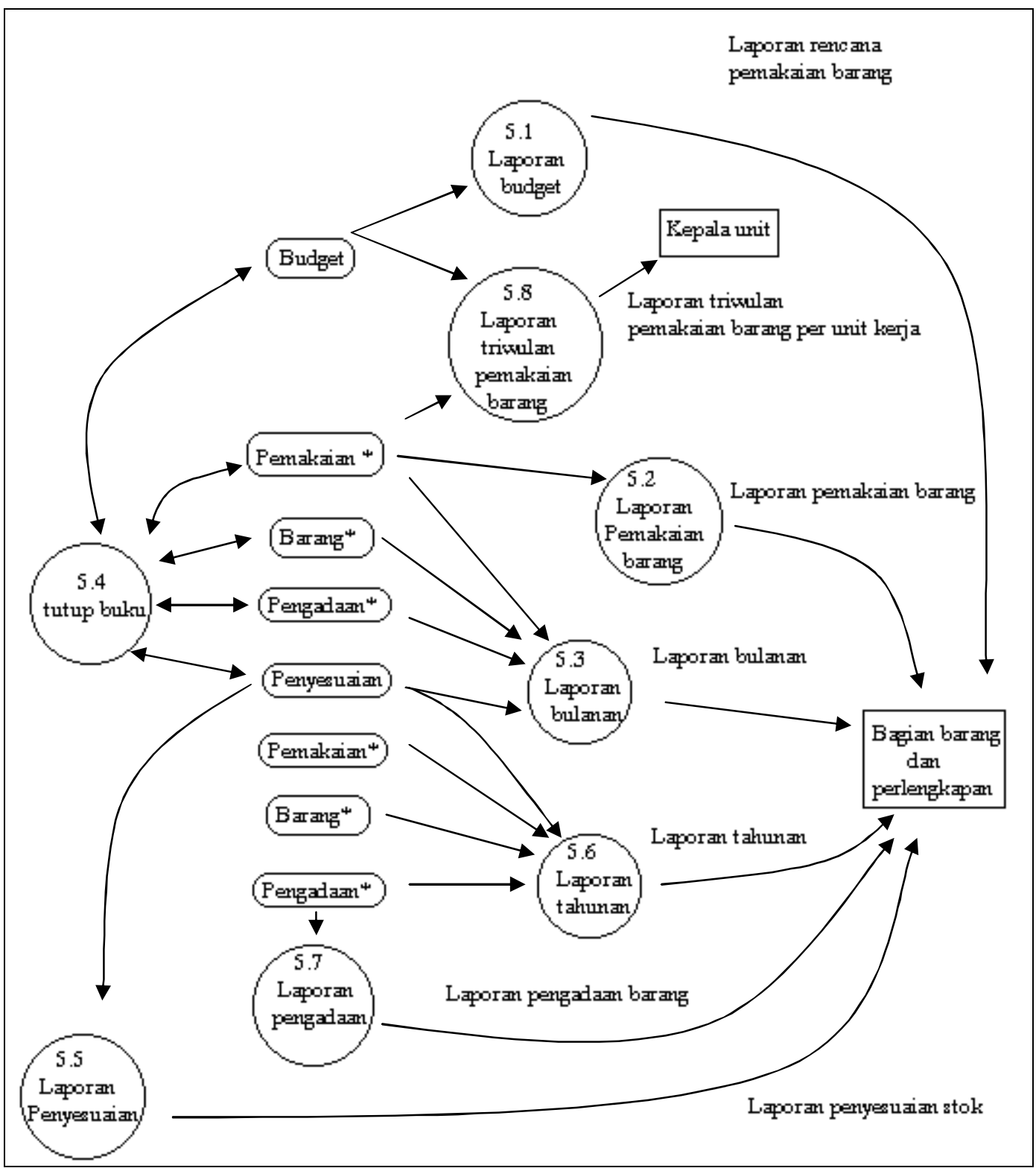

Gambar 3. DFD Level 1 Tutup Buku dan Pelaporan

\subsection{Sistem Procedure}

Prosedur sistem digunakan sebagai manual bagi user untuk menjalankan sistem informasi ini. 


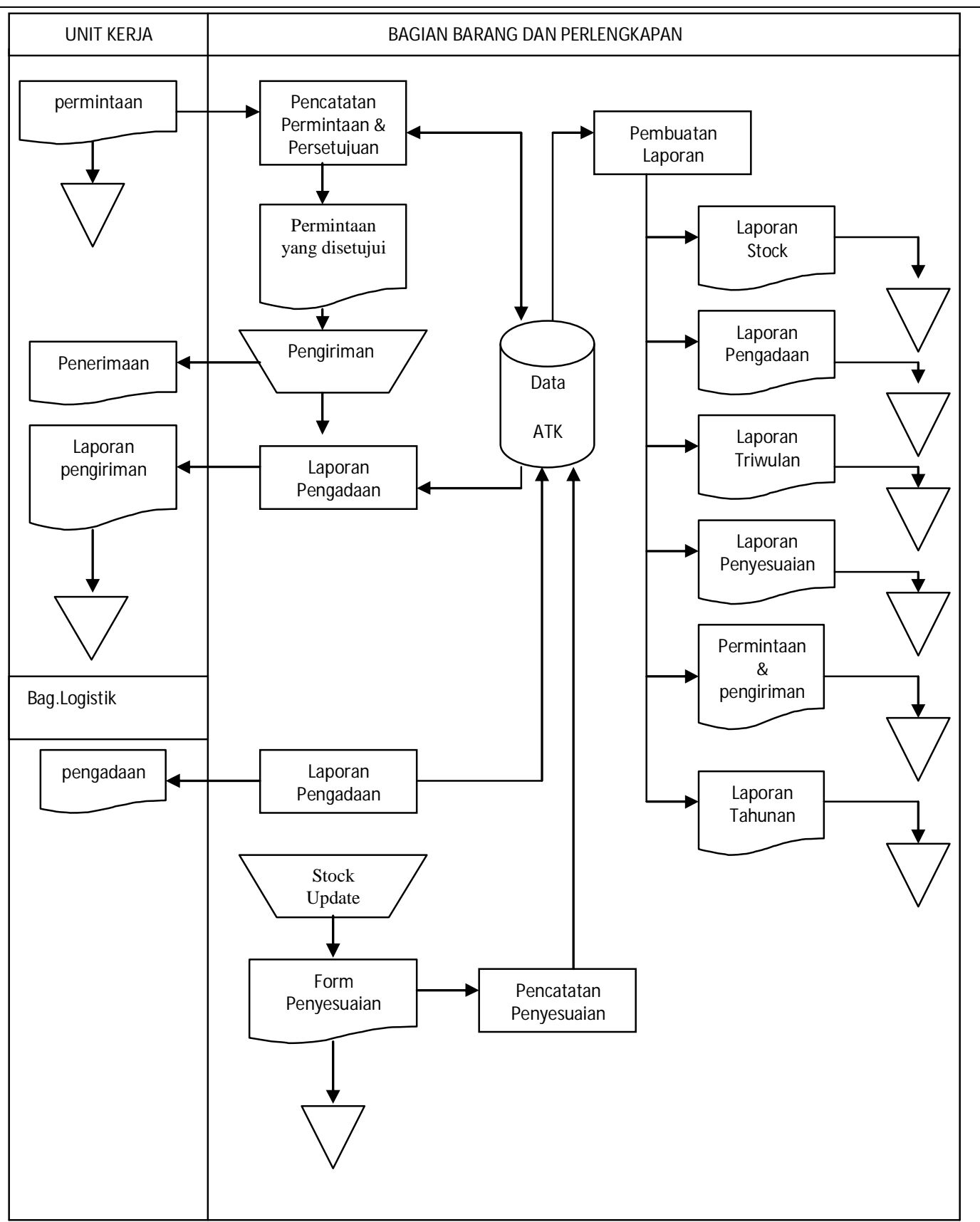

Gambar 4. Prosedur Sistem Informasi Pengelolaan ATK

\section{HASIL DAN PEMBAHASAN}

Bahasa pemrograman yang dipakai adalah bahasa pemrograman script PHP, untuk basis data digunakan MySQL, sedangkan web server yang digunakan adalah Appserv-win32-2.5.

\subsection{Modul Login}

Modul login berfungsi untuk membatasi hanya pengguna yang bersangkutan yang dapat mengakses sistem sesuai dengan peran masing-masing. Pengguna yang tidak bersangkutan akan ditolak. Jika salah memasukkan login maka akan disampaikan pesan kesalahannya. Pada sistem informasi ini terdapat dua login yaitu login untuk user dan login untuk administrator. 


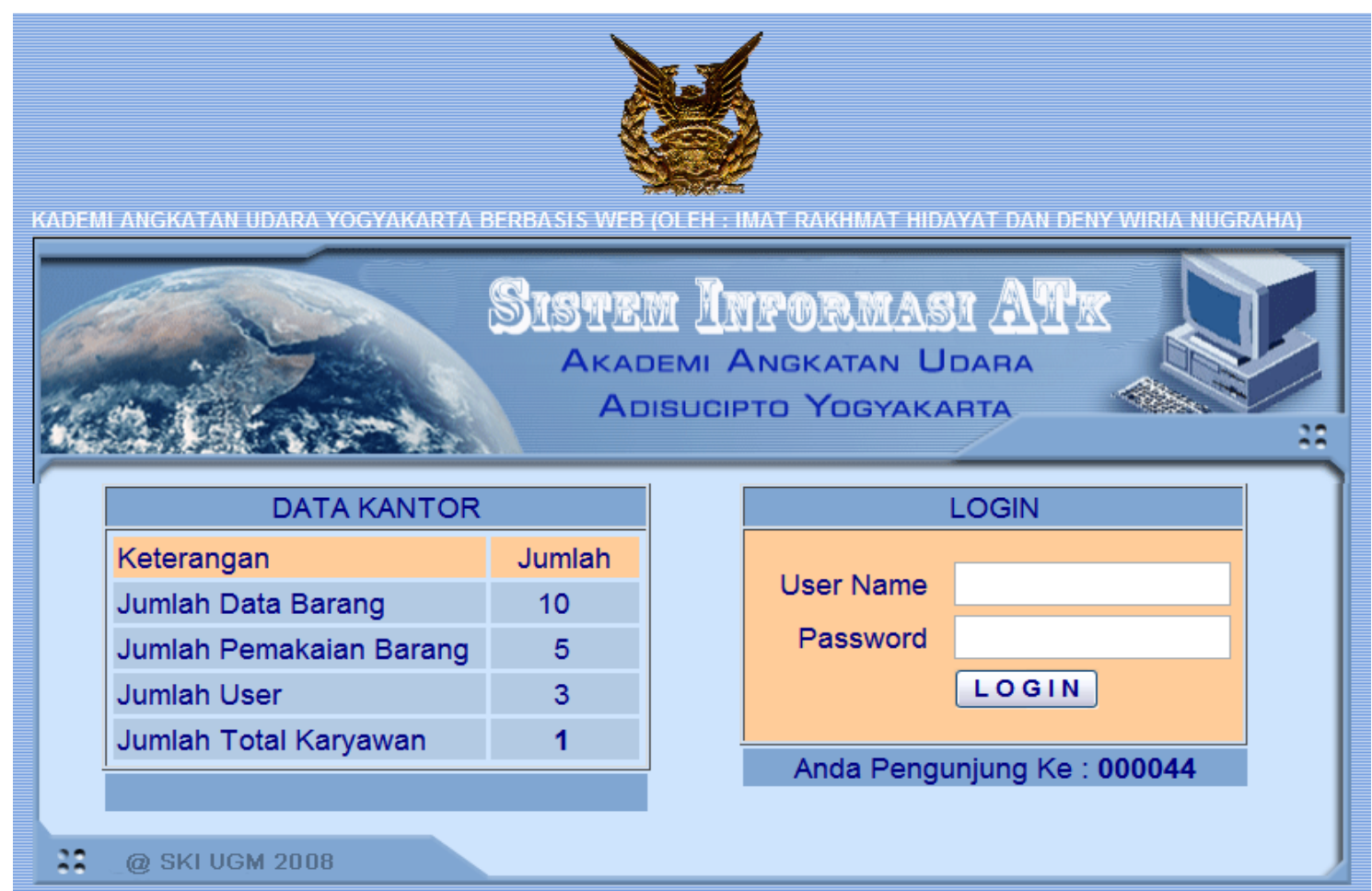

Gambar 5. Login Untuk User

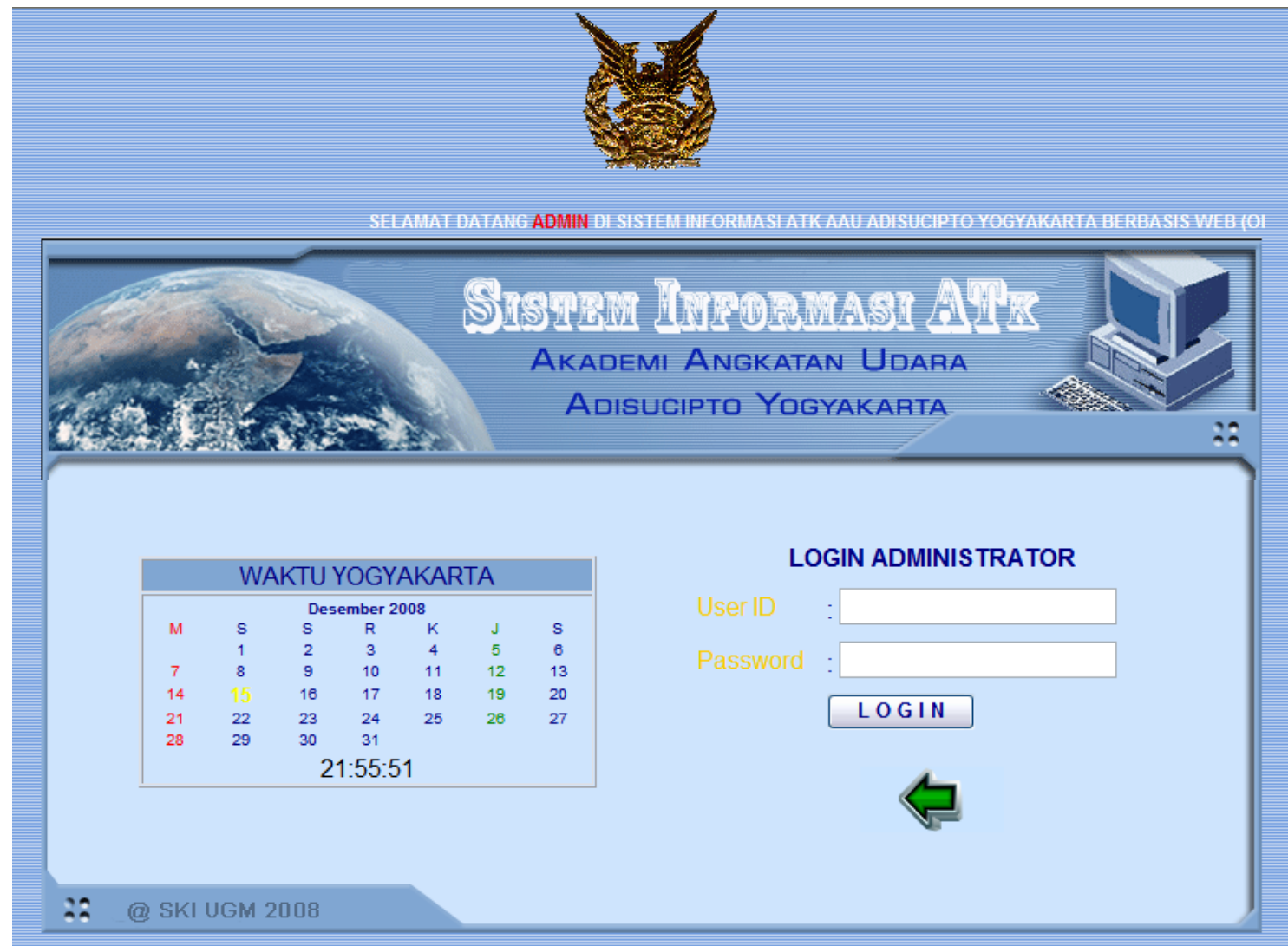

Gambar 6. Login Untuk Administrator 


\subsection{Modul Menu Utama}

Modul menu utama akan menampilkan deskripsi sistem secara singkat. Modul ini membatasi hanya pengguna yang bersangkutan yang dapat mengakses sistem. Modul menu utama ini memiliki beberapa fasilitas layanan. terdapat dua modul menu utama yaitu modul menu utama untuk user dan modul menu utama untuk admin.

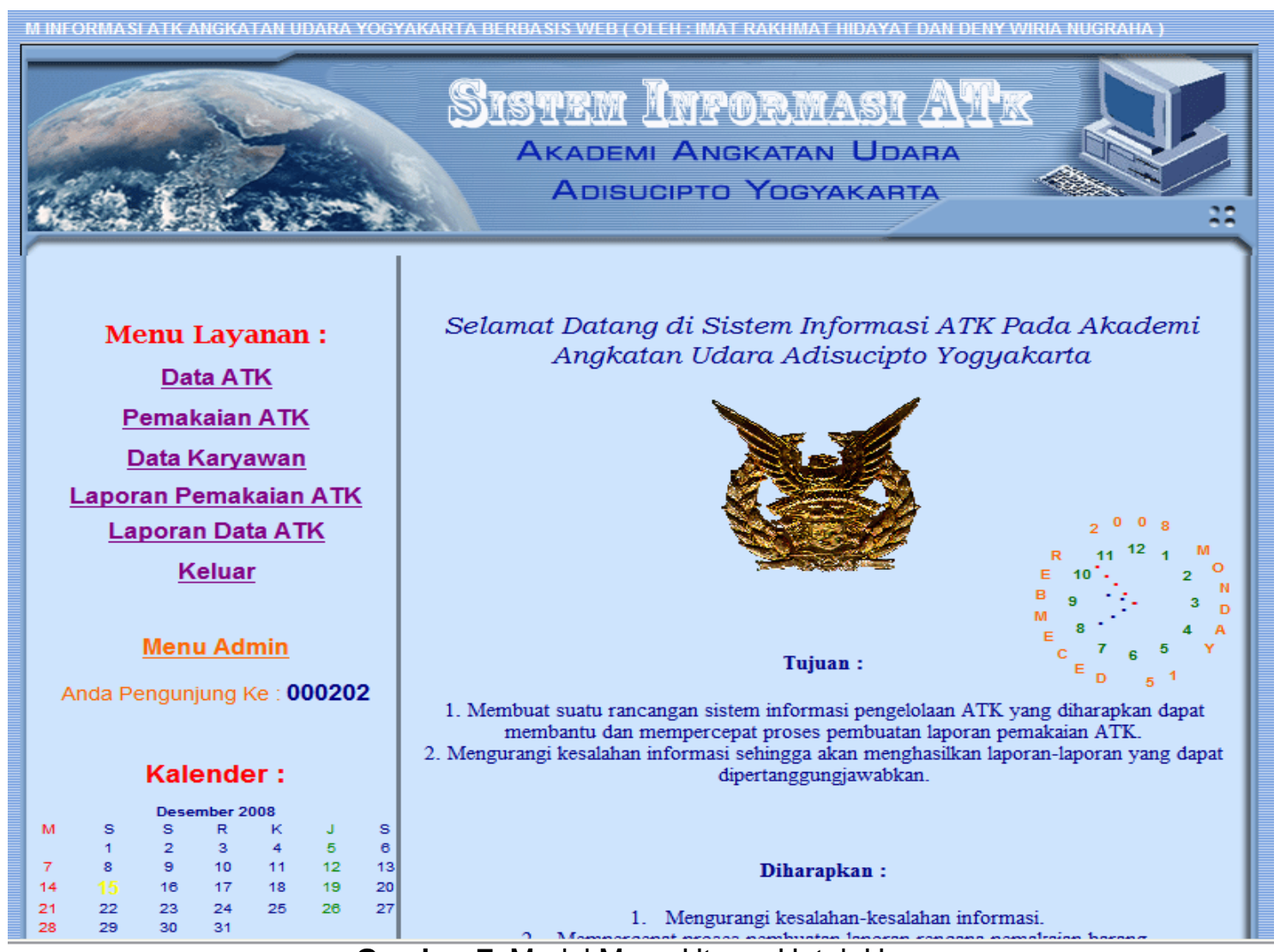

Gambar 7. Modul Menu Utama Untuk User

\subsection{Administrator Sistem}

Administrator sistem dalam hal ini Bagian Perlengkapan mempunyai hak akses terhadap keseluruhan tabel-tabel dalam basis data. la bertanggung jawab atas kelancaran keseluruhan sistem. Hak-hak yang dimiliki oleh administrator sistem adalah sebagai berikut :

- Melihat dan mengatur keseluruhan data dalam basis data.

- Memberikan hak akses kepada seseorang sesuai dengan tugasnya masing-masing dengan memberikan user id dan password kepada orang tersebut.

- Menghapus data-data yang tidak benar, atau tidak jelas asal-usulnya. 


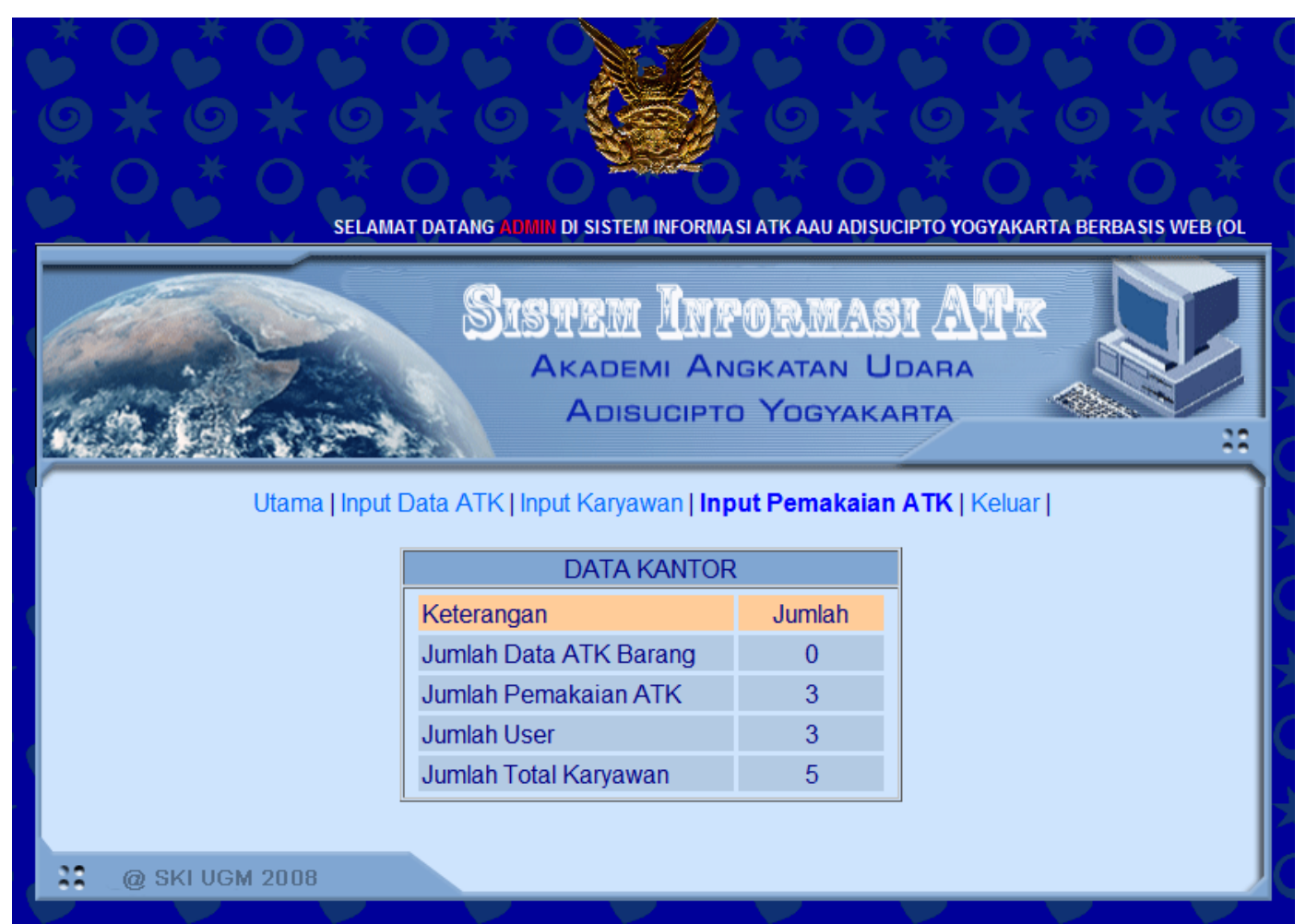

Gambar 8. Modul Menu Utama Untuk Admin

\section{KESIMPULAN}

Kesimpulan yang dapat diambil adalah :

a. Sistem pengelolaan ATK secara manual yang masih digunakan saat ini kurang efektif, kemungkinan terjadinya kesalahan data dan informasi sangat besar.

b. Perancangan sistem ini merupakan pengembangan dari kegiatan pengelolaan ATK yang dilakukan secara manual.

c. Sistem diharapkan dapat membantu dalam Membuat suatu rancangan sistem informasi pengelolaan ATK yang diharapkan dapat membantu dan mempercepat proses pembuatan laporan biaya pemakaian ATK.

d. Sistem aplikasi ini dapat menghasilkan laporan tahunan tentang biaya pemakaian ATK, yang akan menjadi acuan (Bagian Perlengkapan) untuk pengajuan anggaran serta memberikan bukti-bukti yang akurat baik itu penerimaan barang maupun pemakaian barang kepada bagian Logistik.

\section{DAFTAR PUSTAKA}

Jogianto, H.M, 1989, Analisis dan Desain Sistem Informasi, Andi, Yogyakarta.

Jogianto, H.M, 1995, Analisis dan Desain Sistem Informasi : Pendekatan Terstruktur Teori dan Praktek Bisnis, cetakan kelima, Andi, Yogyakarta.

Pressman, Rogers, 1997, Rekayasa Perangkat Lunak : Pendekatan Praktisi, Andi Offset, Yogyakarta.

Martina, Inge, 2003, 36 Jam Belajar Komputer : Microsoft SQL Server 2000, PT. Elex Media Komputindo, Jakarta.

Saaty, TL,1988, Decision Making for Leaders, The Analytical Hierarchy Process for Decision in Complex World, RWS Publications, Pittburrgh

Suryadi, Kadarsah , 2002, Sistem Pendukung Keputusan, Rosda, Bandung. 